\title{
Does the 'Dynamic' bone model applicable for dentine?
}

\begin{abstract}
Nowadays, most of recent adhesive dentistry studies tried to show a great similarity between the 'dynamic' bone model and dentine. The main purpose of this short communication article is to advise the academic community to exert more efforts and direct more research money to conduct some controlled randomized clinical trials in this particular area. Also, to respect the clinical aspects, which is much more complicated compared to the 'simple' laboratory model performed under optimum conditions.
\end{abstract}

Keywords: dentine bonding, matrix metalloproteinases, cysteine cathepsins durability, clinical performance

\author{
Volume 4 Issue 3 - 2016
}

\author{
Hamdi H Hamama \\ Department of Operative Dentistry, Clinical Assistant Professor, \\ Mansoura University, Egypt
}

Correspondence: Hamdi Hosni Hamdan Hamama, Department of Operative Dentistry, Clinical Assistant Professor, Mansoura University, Egypt, Tel +20I I45I77662, Email hamdy@connect.hku.hk

Received: January 16, 2016| Published: March 2, 2016

\section{Introduction}

Nowadays, most of recent adhesive dentistry studies tried to show a great similarity between the 'dynamic' bone model and dentine. Many authors attributed the dentine bonding degradation to the presence of an internal enzymatic activity; matrix metalloproteinases (MMPs) or cysteine cathepsins endopeptidases within the dentine., ${ }^{1,2}$ Most of these studies neglected the great difference between the "bone" model and dentine. Bone is a highly vascular calcified connective tissue contains three types of cells; osteoblasts, osteocytes, and osteoclasts. ${ }^{3}$ Despite of its solid appearance, bone is a highly dynamic organ that is continuously resorbed by osteoclasts and neoformed by osteoblasts. ${ }^{3}$

The current published manuscripts in the field of adhesive dentistry applied the bone-proteolytic systems on dentine without any strong evidence of osteoclystic-activity in dentine. Most of these studies attributed the degradation of resin/dentine interface to the proteolytic activity within the dentine. ${ }^{4}$ Although, this activity may play a 'minor' role in the degradation, the principal role of clinical procedures is usually unconsidered.

Several current 'basic science' studies in adhesive dentistry neglected the long-term clinical success of adhesive restorations which is reported in many published clinical trials. The outcome of the randomized clinical trials (RCT) by Pallesen et al. ${ }^{5,6}$ and Van Dijken et al. ${ }^{7}$ showed that adhesive tooth-colored restorations had good clinical performance after 15, 27 and 30 years. Moreover, the results of the thirteen-year RCT by Peumans et al. ${ }^{8}$ showed that twostep self-etch adhesives had good clinical performance in non-carious cervical lesions.

Based on the 'theoretical' outcome of 'basic science' laboratory studies, most of the adhesive restorations should fail after few years, however this is not clinically applicable. In fact, the majority of the current adhesive studies neglected some important clinical factors for creating successful restorations; isolation of operating field, tissue changes in caries-affected substrate, ${ }^{9}$ the influence of caries removal method, ${ }^{9}$ and clinician's errors during the application of dental adhesives. Also, the type of adhesive restorative materials and the polymerization process play great role on the long-term service of the restoration. The laboratory finding of the studies conducted on isolated collagen fibers assumed that all adhesive/collagen interfaces subjected to some 'theoretical' proteolytic process based on biological findings presented in bone models. Hence, the trend of contemporary adhesive research is to discover a new material for inhibition of the proteolytic activity in dentine.

The critical question is "Can dentine proteolytic-activityinhibitors separately solve the degradation problem and create long-lasting restorations?" Therefore, the main purpose of this short communication article is to advise the academic community to exert more efforts and direct more research money to conduct some controlled randomized clinical trials in this particular area. Also, to respect the clinical aspects, which is much more complicated compared to the 'simple' laboratory model performed under optimum conditions.

\section{Funding}

None.

\section{Acknowledgements}

None.

\section{Conflicts of interest}

Author declare that there is no conflict of interest.

\section{References}

1. Abu Nawareg M, Elkassas D, Zidan A, et al. Is chlorhexidinemethacrylate as effective as chlorhexidine digluconate in preserving resin dentin interfaces?. J Dent. 2015;45:7-13.

2. Scheffel D, Delgado CC, Soares DG, et al. Increased Durability of Resin-Dentin Bonds Following Cross-Linking Treatment. Oper Dent. 2015;40(5):533-539.

3. Florencio-Silva R, Sasso GR, Sasso-Cerri E, et al. Biology of Bone Tissue: Structure, Function, and Factors That Influence Bone Cells. Biomed Res Int. 2015:421746. 
4. Sabatini C, Pashley DH. Mechanisms regulating the degradation of dentin matrices by endogenous dentin proteases and their role in dental adhesion A review. Am J Dent. 2014; 27(4):203-214.

5. Pallesen U, van Dijken JW. A randomized controlled 27 years follow up of three resin composites in Class II restorations. J Dent. 2015;43(12):15471558.

6. Pallesen U, van Dijken JW. A randomized controlled 30 years follow up of three conventional resin composites in Class II restorations. Dent Mater. 2015;31(10):1232-1244.

7. van Dijken JW, Lindberg A. A 15-year randomized controlled study of a reduced shrinkage stress resin composite. Dent Mater. 2015;31(9):1150 1158.
8. Peumans M, De Munck J, Van Landuyt K, et al. Thirteen-year randomized controlled clinical trial of a two-step self-etch adhesive in non-carious cervical lesions. Dent Mater. 2015;31(3):308-314.

9. Hamama HH, Yiu CK, Burrow MF. Effect of chemomechanical caries removal on bonding of self-etching adhesives to caries-affected dentin. $J$ Adhes Dent. 2014;16(6):507-516. 